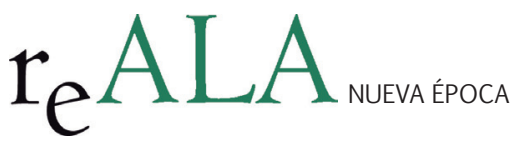

REALA, n 1, enero-junio 2014, ISSN: 1989-8975

DOI: http://dx.doi.org/10.24965/reala.voi1.10143

\title{
La atribución de competencias para la implantación de determinadas instalaciones y la autonomía local
}

\author{
Fernando Camón Fernández de Ávila \\ Ayuntamiento de Badalona \\ fcamon@badalona.cat
}

Recibido: 6 de mayo de 2013

Aceptado: 4 de noviembre de 2013

Resumen

La implantación territorial de determinadas instalaciones que, potencialmente, pueden generar mucha riqueza a los municipios donde se ubiquen, provoca frecuentemente controversias entre los diferentes niveles de Administraciones territoriales a la hora de determinar a cuál corresponde su autorización, y en función de qué criterios y título jurídico. Este trabajo analiza algunos ejemplos y propone la consideración de determinados elementos como medio de resolución de las discusiones competenciales.

Palabras clave

Autonomía local, principio de subsidiariedad, principios y criterios de actuación de las Administraciones públicas, régimen de autorización

\section{The Atribution of Competency for the Implantation of certain Facilities and the Local Autonomy}

\section{Abstract}

The territorial implementation of certain facilities that can potentially generate a lot of wealth to the municipalities where they are located often causes disputes between the different levels of local authorities when determining to which corresponds the authorization, and depending on what criteria and legal title. This paper discusses some examples and proposes the consideration of certain elements as a means of resolving the jurisdictional arguments.

\section{Keywords}

Local Autonomy, Principle of subsidiarity, Principles and criteria for government action, Authorization regime 


\author{
SUMARIO \\ 1. Introducción \\ 2. Los almacenes nucleares \\ 3. Los complejos turísticos lúdico-recreativos \\ 4. Los grandes centros de distribución comercial. El ejemplo catalán \\ 5. Conclusiones: La atribución y el reparto de las competencias desde el punto de vista jurídico \\ 6. Nota final \\ 7. Bibliografía
}

\title{
INTRODUCCIÓN
}

Las decisiones sobre implantación de determinadas instalaciones o equipamientos que potencialmente pueden tener unas consecuencias económicas trascendentales para sus puntos de ubicación ocasionan frecuentemente controversias tanto sobre su oportunidad o conveniencia desde diferentes perspectivas como sobre la competencia de las Administraciones que han de decidir sobre la materia.

Efectivamente, y más aún en un contexto de acusada y prolongada crisis económica como la que estamos atravesando, es frecuente asistir a una especie de pugna entre diversos municipios o zonas por acoger tales instalaciones, pugna que en ocasiones más adquiere ribetes de puja, en el sentido de ofrecer a sus promotores cualquier ventaja digna de su atención que no ofrezcan otros municipios, con tal de lograr convencerles de las bondades de cada ubicación propuesta. Así, con independencia de las discusiones de naturaleza puramente política o ideológica (me estoy refiriendo a los aspectos que tienen que ver con la ecología y la sostenibilidad, tales como criterios medioambientales, de movilidad, de protección del entorno y el paisaje, etcétera), asistimos con frecuencia a discusiones sobre quién debería ser la autoridad competente para tomar tales decisiones.

En este sentido, es preciso recordar que la Directiva 2006/123/CE, del Parlamento Europeo y del Consejo, de 12 de diciembre de 2006, relativa a los servicios en el mercado interior (en adelante, DSMI), promueve, entre otras cosas, la eliminación de barreras que obstaculizan el desarrollo de las actividades económicas de servicios. Así, su artículo 1 ya nos adelanta que su objetivo es facilitar el ejercicio de la libertad de establecimiento de los prestadores de servicios y la libre circulación de los servicios, manteniendo un elevado nivel de calidad de los mismos, para lo que se restringe la posibilidad de someter el acceso a la actividad de servicios y su ejercicio (artículo 9) a un régimen de autorización, salvo que tal régimen esté justificado por razones imperiosas de interés general, que sea proporcional (es decir, no pueda alcanzarse con medidas menos estrictas) y que no sea discriminatorio para el prestador. El artículo 10 completa este enfoque con la enumeración de las características que han de reunir los criterios por los que se puede ejercer tal facultad de autorización, que a las ya dichas añade las de que sean claros e inequívocos, objetivos, conocidos y publicados con antelación, transparentes y accesibles. Cuando se cumplan todas estas características, pues, podremos considerar que el sometimiento de una actividad económica de servicios a un régimen de autorización estará justificado.

La tardía transposición de esta Directiva a nuestro ordenamiento jurídico se ha efectuado (podríamos decir que aún se está efectuando) tanto mediante leyes estatales como autonómicas, así como mediante la adaptación de ordenanzas y reglamentos de los diferentes entes locales. No siendo el análisis de estas reflexiones un estudio exhaustivo de la DSMI ni de sus mecanismos de transposición a nuestra legislación, nos limitaremos a constatar que esta normativa proyecta un enfoque nuevo que forzosamente comporta consecuencias en cuanto a la distribución de las competencias entre las diferentes Administraciones intervinientes. Y ello es así no únicamente ex lege ni ope legis, sino a causa de los criterios que acabamos de enumerar, y principalmente del concepto de "razones imperiosas de interés general" que la propia DSMI se encarga de definir: "razón reconocida como tal en la jurisprudencia del Tribunal de Justicia, incluidas las siguientes: el orden público, la seguridad pública, la protección civil, la salud pública, la preservación del equilibrio financiero del régimen de seguridad social, la protección de los consumidores, de los destinatarios de servicios y de los trabajadores, las exigencias de la buena fe en las transacciones comerciales, la lucha contra el fraude, la protección del medio ambiente y del entorno urbano, la sanidad animal, la propiedad intelectual e industrial, la conservación del patrimonio histórico y artístico nacional y los objetivos de la política social y cultural" (artículo 4.8). Efectivamente, el hecho de que tales criterios sean los que permiten el establecimiento de un régimen de autorización comporta que las autoridades concernidas hayan de examinar si el supuesto habilitante entra o no dentro de sus competencias. Así, por ejemplo, un Ayuntamiento español no podrá argumentar la protección de la propiedad intelectual e industrial como criterio para implantar un régimen de autorización, puesto que tal materia no figura entre las que son de competencia municipal según la Ley 7/1985, de 2 de abril, Reguladora de las Bases del Régimen Local (LRBRL, en adelante); en cambio, sí podrá hacerlo cuando el motivo invocado sea la protección del medio ambiente y el entorno urbano, por ejemplo. 
Nótese, no obstante, que la Ley 17/2009, de 23 de noviembre, sobre el libre acceso a las actividades de servicios y su ejercicio (conocida como Ley Paraguas), encargada de la transposición de la DSMI, con una redacción francamente defectuosa, nos define la "razón imperiosa de interés general", en su artículo 3.11, como la "razón definida e interpretada la jurisprudencia del Tribunal de Justicia de las Comunidades Europeas, limitadas las siguientes: el orden público, la seguridad pública, la protección civil, la salud pública, la preservación del equilibrio financiero del régimen de seguridad social, la protección de los derechos, la seguridad y la salud de los consumidores, de los destinatarios de servicios y de los trabajadores, las exigencias de la buena fe en las transacciones comerciales, la lucha contra el fraude, la protección del medio ambiente y del entorno urbano, la sanidad animal, la propiedad intelectual e industrial, la conservación del patrimonio histórico y artístico nacional y los objetivos de la política social y cultural". Así, mientras el listado de la DSMI es un sistema abierto a las decisiones actuales y futuras del Tribunal de Justicia, dado que incluye una lista de razones no cerrada, el de la Ley Paraguas es un listado cerrado ("limitadas las siguientes"). Ello significa que en el futuro, si el Tribunal de Justicia europeo ampliara esta lista de razones, tal ampliación aparentemente no sería de aplicación en España, al menos de manera automática, ya que no figura en la lista cerrada de la Ley española.

Por otra parte, desde el punto de vista local, resulta interesante el matiz introducido por la Ley Paraguas en el tema de la protección de los consumidores: si la Directiva considera como "razón imperiosa de interés general" la protección de los consumidores, la Ley especifica "la protección de los derechos, la seguridad y la salud de los consumidores". ¿Tiene alguna trascendencia especial esta especificación? El Preámbulo de la Ley no nos indica nada en este aspecto. Pero, en un sentido negativo, sí que podemos adivinar la causa del matiz: el concepto "protección" de los consumidores es un concepto amplio, genérico, susceptible (como todo concepto jurídico indeterminado) de diversas interpretaciones; en cambio, si delimitamos la protección a los "derechos, la seguridad y la salud" de los consumidores, estamos acotando este campo de manera que la interpretación ha de ser más restrictiva. A modo de ejemplo: la decisión de autorizar o no un centro comercial en un lugar determinado puede ser diferente si se utiliza el concepto "intereses de los consumidores" (no recogido en la Ley) como razón imperiosa de interés general integrante de la "protección de los consumidores", que si se restringe a los derechos (reconocidos legalmente como tales), la seguridad y la salud de los consumidores. Y la LRBRL nos dice en este sentido (artículo 25.2.g) que los municipios ejercen competencias, en los términos de la legislación del Estado y de las Comunidades Autónomas, en materia de defensa de usuarios y consumidores, sin especificar el contenido de tal materia como hace la Ley Paraguas...

Observamos así que, a la hora de determinar la Administración competente para autorizar una instalación singular en un lugar concreto, hemos de tener presente la regulación europea y estatal (incluyendo la autonómica, claro está) relacionada con la DSMI, además de atender a la normativa de atribución competencial, que es a la que se refiere preferentemente este artículo.

En relación con todo ello, examinaremos a continuación tres tipologías de establecimientos o instalaciones que resultan particularmente interesantes desde esta doble perspectiva que hemos comentado: los cementerios o almacenes nucleares, los complejos turísticos lúdico-recreativos y los grandes establecimientos comerciales.

\section{LOS ALMACENES NUCLEARES}

El tema candente de la ubicación de los comúnmente denominados cementerios nucleares en el territorio español ha suscitado, aparte de controversias planteadas desde el punto de vista medioambiental o ecologista, un debate sobre la competencia de los Ayuntamientos para tomar las decisiones que consideren oportunas, a partir del principio de autonomía local, y todo ello por cuanto tales equipamientos están sometidos a un régimen de autorización (licencia) por cuanto inciden claramente, o pueden incidir, en el medio ambiente o la protección civil y la salud pública, entre otros aspectos.

El principio de autonomía local ha sido esgrimido por los Ayuntamientos (y otros grupos de presión diversos) como el fundamento de su libre elección en orden a solicitar tales instalaciones, las cuales, obviamente, generan una serie de ingresos y recursos económicos de carácter más o menos duradero, directos e indirectos. Y este principio se contrapone frente a cualquier tipo de ingerencia de Administraciones de ámbito territorial superior, puesto que ceder a los planteamientos de tales Administraciones supralocales equivaldría a desvirtuar el principio de autonomía local.

No entraremos en el debate ecologista o medioambiental, ni en la reflexión sobre el balance ventajas/desventajas (el típico análisis DAFO) que para un pueblo cualquiera puede comportar una instalación de este tipo. Interesa más bien analizar si la invocación del principio de autonomía local se efectúa con corrección desde el punto de vista jurídico, y ello teniendo en cuenta los principios de interpretación del derecho que desde tiempo casi inmemorial deriva nuestra jurisprudencia del Código Civil (sistemático, teleológico, etc.). 
En este sentido, interesa recordar que el principio de autonomía local está recogido expresamente en nuestro ordenamiento jurídico a partir de los artículos 137 y 140 de la Constitución Española (CE), los cual estipulan que los municipios (entre otras Administraciones territoriales) gozan de autonomía para la gestión de sus intereses. Tales preceptos han sido convenientemente desarrollados tanto en la LRBRL como en las diferentes leyes autonómicas que ordenan sus respectivos regímenes locales, y no hace falta entrar en su análisis pormenorizado porque el objeto de estas reflexiones no es elaborar una lección magistral sino analizar las implicaciones y consecuencias prácticas del tema que nos ocupa.

Por lo tanto, teniendo en cuenta que la autonomía local se predica en la CE en relación con la gestión de los intereses municipales, hemos de comprobar en primer lugar si el objeto de esta materia (los almacenes nucleares) entra dentro de los intereses o competencias municipales. En tal sentido, y por no entrar en un análisis detallado de cada una de las regulaciones del mundo local existentes en nuestro Estado de las autonomías, me referiré con carácter general a la LRBRL, dado que se trata de una Ley aplicable a todo el Estado español.

Recordemos, de entrada, que su artículo 4 reconoce a los Ayuntamientos, entre otras potestades, la de programación o planificación. No parece caber duda de que tal potestad no ha de predicarse únicamente "ad intra", o como mecanismo de organización, sino que también puede ser relativa a la planificación "ad extra", externa, orientada a definir cómo se desea que se configure la vida de un municipio concreto, dentro siempre del marco legal. No tendría sentido, en caso contrario, atribuir a los Ayuntamientos competencias en materia de ordenación urbanística, por poner un ejemplo. En resumen, y por no extenderme en obviedades: los municipios disponen de autonomía para gestionar los intereses que las leyes les atribuyen como propios de sus competencias. Al respecto, un primer análisis ha de referirse a qué se entiende como "intereses" de los municipios. Podemos recordar en tal sentido la apreciación de Mir i Bagó', según la cual constituyen intereses municipales todos aquellos aspectos de la vida colectiva que afectan de una manera singular o especial a una determinada colectividad, y ésta lo percibe precisamente así (la definición expresada recuerda bastante a la doctrina del TC, manifestada en su sentencia 32/1981, F.J. $3^{\circ}$, donde se dice que "la garantía institucional (de la autonomía local) no asegura un contenido concreto o un ámbito competencial determinado y fijado de una vez por todas, sino la preservación de una institución en términos reconocibles para la imagen que de la misma tiene la conciencia social en cada tiempo y lugar. Dicha garantía es desconocida cuando la institución es limitada de tal modo que se le priva prácticamente de sus posibilidades de existencia real como institución para convertirse en un simple nombre").

Según el mismo autor, se puede defender, a partir de este planteamiento, una capacidad general de iniciativa de los municipios y provincias, más allá de las competencias expresas que les atribuyen las leyes. De acuerdo con este postulado del autor citado, la defensa de los intereses que afectan a los municipios se constituye en una razón de ser de la actuación municipal, e incluso en una obligación que puede ser instada por los vecinos en caso de inacción del Gobierno local (artículo 68 LRBRL).

Por tanto, y siguiendo este razonamiento, allá donde nos hallemos ante una defensa de los intereses municipales, en principio habremos de apostar por la defensa a ultranza de la autonomía local, y todo ello desde el prisma de las competencias legalmente atribuidas a los municipios.

Sobre ello, es interesante recalcar que tanto la protección del medio ambiente como de la salubridad pública, o la protección civil, son competencias municipales recogidas expresamente en la LRBRL (art. 25.2), mientras que el fomento del empleo o el desarrollo económico (razones profusamente argüidas para justificar la solicitud de instalación de un cementerio nuclear) se vehiculan a través de la que podríamos conceptuar como cláusula abierta del artículo 25.1, cuando atribuye a los municipios una competencia genérica para "promover toda clase de actividades y prestar cuantos servicios públicos contribuyan a satisfacer las necesidades y aspiraciones de la comunidad vecinal". Así, de entrada, podemos contraponer unas competencias ex lege a otras de carácter potestativo o facultativo. Pero otro enfoque contribuye a introducir más confusión. En efecto, la propia LRBRL (artículo 26) define como servicios de prestación obligatoria para los municipios, entre otros, el de protección civil (sólo a partir de 20.000 habitantes) o la protección del medio ambiente (sólo a partir de 50.000 habitantes). ¿Quiere ello decir que los de lindares de población inferior a dichas cifras están exentos de la obligación de prestar tales servicios, o, lo que es lo mismo, que las personas que viven en una ciudad de 49.999 habitantes no tienen derecho a la protección de su medio ambiente? Evidentemente, no. Para ello dispone el mismo artículo 26 que las Diputaciones y/o las Comunidades Autónomas prestarán la asistencia debida a los municipios que lo necesiten. Lo contrario, obviamente, conculcaría el principio básico de igualdad ante la ley de todos los españoles que la CE configura como uno de sus elementos fundamentales.

Y por aquí podemos empezar a atisbar una luz en el tema que nos ocupa: la intervención subsidiaria de Administraciones supramunicipales allá donde no llegan los Ayuntamientos con sus recursos propios. En tal sentido,

1 MIR I BAGÓ, J.: Manual de Govern Local. Federació de Municipis de Catalunya, Barcelona, 2000, p. 49. 
resulta de especial interés consultar la Carta Europea de Autonomía Local, hecha en Estrasburgo el 15 de octubre de 1985 (CEAL), que forma parte de nuestro ordenamiento jurídico, y es por tanto directamente aplicable, desde su ratificación por el Reino de España el 20 de enero de 1988 y su publicación en el B.O.E. el 24 de febrero de 1989.

La CEAL dice textualmente, en su artículo 4, puntos 2 y 3, lo siguiente: "2. Las entidades locales tienen, dentro del ámbito de la Ley, libertad plena para ejercer su iniciativa en toda materia que no esté excluida de su competencia o atribuida a otra autoridad. 3. El ejercicio de las competencias públicas debe, de modo general, incumbir preferentemente a las autoridades más cercanas a los ciudadanos. La atribución de una competencia a otra autoridad debe tener en cuenta la amplitud o la naturaleza de la tarea o las necesidades de eficacia o economía".

Esta disposición acoge, claramente, los rasgos definitorios de lo que se entiende por principio de subsidiariedad: como bien dicen Elvira Fernández y Eva Giménez², por una parte significa que los poderes públicos han de residir en la instancia más próxima al ciudadano, y por otra se manifiesta como un principio clave en las relaciones interadministrativas que muestra las condiciones que han de presidir el traspaso de poderes a un ente superior. Estas condiciones están vinculadas a la garantía de una prestación de servicios a la ciudadanía de mejor calidad, a partir de la constatación de que la autoridad más cercana al ciudadano no dispone de los medios o recursos suficientes para tal cometido, y es por ello por lo que se avoca, por parte de una Administración territorial superior, el ejercicio de tal prestación. Se trata, en el fondo, de un trasunto de uno de los principios que aparecen frecuentemente en el acervo comunitario, cual es el de proporcionalidad: adoptar en cada caso la medida que se considere más adecuada para los fines generales perseguidos.

La preocupación general por la eficacia de los servicios públicos que se deriva de toda la normativa comentada la hallamos, además de en la CE, en la Ley 30/1992, de Régimen Jurídico de las Administraciones Públicas y del Procedimiento Administrativo Común (LRJAP), de 26 de noviembre, modificada por la Ley 4/1999 de 13 de enero. Así, ya la Exposición de Motivos de la Ley de 1992 hace referencia (apartado 4) a la necesidad de acercar de manera eficaz los servicios públicos a los ciudadanos, para lo que se hace indispensable la cooperación entre las diversas Administraciones públicas. Del mismo modo, el apartado 2 de la Exposición de Motivos de la Ley 4/1999 menciona el principio de lealtad institucional como criterio rector que facilite la colaboración y la cooperación entre las diferentes Administraciones públicas. Y ya en la parte dispositiva, el artículo 3.1 de la LRJAP menciona el principio de eficacia, y el artículo 3.2 estipula que las Administraciones públicas, en sus relaciones, se rigen por el principio de cooperación y colaboración, y en su actuación por los criterios de eficiencia y servicio a los ciudadanos; mientras que el artículo 4.1 recoge el principio de lealtad institucional, a partir del cual las Administraciones deberán respetar el ejercicio legítimo por las otras Administraciones de sus competencias. Nótese, por otra parte, que el apartado 3 de este mismo artículo contempla como una excepción al deber de cooperación el supuesto de que el ente del que se solicita no esté facultado para prestarla, no disponga de medios suficientes para ello, o cuando pueda causarse un perjuicio grave a los intereses cuya tutela tenga encomendada o al cumplimiento de sus propias funciones. Vemos así que recurrentemente aparecen entrelazados los conceptos de eficacia y competencia, tan unidos al principio de subsidiariedad.

Pues bien, y a partir de tales reflexiones: la decisión de instalar un almacén nuclear que pudiere adoptar un Ayuntamiento concreto, ¿tiene en cuenta "la amplitud o la naturaleza de la tarea o las necesidades de eficacia o economía" a que se refiere el artículo 4.3 de la CEAL? O, dicho de otro modo: ¿corresponde exclusivamente a tal Ayuntamiento la adopción de la decisión pertinente, teniendo en cuenta que sus efectos potenciales (en materia de protección de la salubridad, del medio ambiente, etc.) son, al menos en teoría, susceptibles de extenderse a otros municipios?

Parece evidente que, tal como acordó la Asamblea extraordinaria de la Federación Española de Municipios y Provincias celebrada en La Coruña en un lejano mes de noviembre de 1993, las instancias territoriales superiores sólo habrán de asumir aquellas competencias que no sea posible residenciar en la Administración Local. Pues bien, a la luz de tal criterio: ¿es la seguridad potencial, actual y futura, de una instalación de almacenamiento de residuos nucleares un ámbito o competencia propia exclusivamente de un determinado Ayuntamiento? Si los científicos expertos en la materia así lo aseveran, no hay ningún problema en residenciar la cuestión únicamente en el principio de autonomía local. Pero si no fuera así, pues habrá de entrar en juego la cara negativa del principio de subsidiariedad, en el sentido de que la Administración de ámbito territorial superior que abarque toda la zona potencialmente afectada tendrá la obligación de asumir las competencias correspondientes³.

2 ELVIRA FERNANDEZ y EVA GIMENEZ. “Els principis de subsidiarietat, proporcionalitat, descentralització i autonomia local i les seves conseqüències per a la regulació del règim local a Catalunya”. Ponencia presentada en el Seminario sobre "Gobierno local y organización territorial: subsidiariedad y descentralización”, organizado por el Consorcio Universidad Internacional Menéndez Pelayo de Barcelona, Centro Ernest Lluch. Barcelona, 8 y 9 de octubre del 2001.

3 Ver en este sentido, J. AROZAMENA SIERRA (Coord.), El Derecho Local en la Doctrina del Consejo de Estado, Consejo de Estado, Imprenta Nacional del Boletín Oficial del Estado, Madrid, 2002, p. 16-17. 
Así que no podemos, desde el punto de vista jurídico, ampararnos sin más en el principio de autonomía local para decidir si un Ayuntamiento está legitimado para solicitar y decidir la instalación en su término municipal de un cementerio nuclear sin consultar con otras Administraciones de ámbito territorial superior, porque una gran mayoría de los efectos prácticos de tal decisión afectará posiblemente a muchos ciudadanos no empadronados en tal municipio. Y ello justamente puesto que tal interpretación contraviene el principio de subsidiariedad, porque la autonomía local, en efecto, se complementa (se ayunta, si se permite el uso del castellano antiguo) con el principio de subsidiariedad en el sentido que hemos explicado y que recoge la jurisprudencia.

Y nótese también que tal invocación del principio de subsidiariedad no incumbe o afecta únicamente a los municipios que hayan solicitado la ubicación de almacenes nucleares, sino que como criterio general será de aplicación a cualquier otra instalación cuya implantación afecte a zonas de mayor extensión territorial.

Lo que nos lleva a una reflexión empírica del mayor interés: El riesgo de que se produzca un accidente nuclear grave (recordemos Chernóbil o Fukushima) o no nuclear (recordemos Bhopal, en la India) que afecte a grandes extensiones de terreno, en nuestro caso dentro de la Unión Europea, comporta la obligatoriedad de que la autorización de tales instalaciones competa a la Administración territorial que abarque toda la zona potencialmente afectada, como hemos visto. Si una central nuclear situada a 150 kilómetros de España, en Francia (por ejemplo) corriera el riesgo de sufrir un accidente grave que pudiera contaminar a Cataluña y Aragón, ¿no debiera haber sido autorizada tal instalación conjuntamente entre España y Francia, o, en caso de desacuerdo, directamente por la Unión Europea? Ya sé que tal propuesta es hoy una entelequia, dado el nivel de integración europea que experimentamos. Pero sí considero que tal razonamiento es plenamente aplicable a nivel interno, estatal: Ascó está muy cerca de la Comunidad Valenciana; Zarra, muy cerca de Castilla-La Mancha, etcétera. ¿Han de adoptar las decisiones correspondientes no ya los Ayuntamientos - de lo expuesto hasta ahora se desprende mi opinión contraria- sino tan sólo las Comunidades Autónomas donde se hallan, dado que su alcance potencial trasciende sus propias fronteras? ¿Ha de ser la decisión fruto de un acuerdo obligatorio entre las Comunidades Autónomas concernidas, acuerdo que puede no alcanzarse (recordemos las discrepancias en materia de trasvases hídricos)? Pues no, entiendo que por las razones de interés general concurrentes en el supuesto, debiera ser el Estado central quien tomara tal decisión, previas las consultas y negociaciones políticas que se quiera, y con las compensaciones que se decida.

Así que no enfrentemos a los Ayuntamientos con otros Ayuntamientos, ni con las Comunidades Autónomas, ni a éstas entre sí, en función de un sedicente principio de autonomía local que no es invocable en esta materia so pena de desvirtuarlo haciendo un uso más que torticero del mismo. La discusión puede tener todo el alcance político que los partidos políticos deseen por sus propias razones o sus propios intereses, pero la resolución de la controversia es de naturaleza jurídica. Porque se está discutiendo todo el asunto a partir de una interpretación a mi juicio errónea del principio constitucional de autonomía local, así como del concepto de competencias autonómicas. Y dudo que los diferentes servicios jurídicos de las distintas Administraciones implicadas no compartan este análisis, sino que más bien entiendo que reciben el encargo de revestir de apariencia legal acuerdos cuyo origen son de tipo netamente político, no técnico ni legal.

Y porque en esta materia, y en todas aquellas que transcienden el ámbito territorial de un ente local, no es sólo el principio de autonomía local el que ha de guiarnos, sino también el no siempre bien entendido principio de subsidiariedad. Por lo tanto, compete al Gobierno de España la decisión sobre la ubicación del cementerio nuclear, pero no a petición de determinados Ayuntamientos en función de un mal interpretado principio de autonomía local, sino todo lo contrario: a partir de la aplicación plena, strictu sensu, del principio de subsidiariedad, a partir del análisis de los intereses generales en juego. Y todo ello, sin duda, sin perjuicio de las compensaciones de carácter económico que se asignen al municipio afortunado (o no, según los diferentes puntos de vista), y asumiendo el coste político, en su caso, de la decisión que se adopte. Porque, a fin de cuentas, eso es lo que se espera de los Gobiernos en general, no que se pasen unos a otros las "patatas calientes". También para eso está, repito, el principio de subsidiariedad.

\section{LOS COMPLEJOS TURÍSTICOS LÚDICO-RECREATIVOS}

Otro caso de actualidad es la propuesta para la implantación en España de un complejo turístico, de ocio, residencial, al modo del modelo de la ciudad de Las Vegas (EEUU), conocido como "Eurovegas" y promovido por el magnate estadounidense Sheldon Adelson. Tal persona fue recibida con todos los honores por los máximos responsables políticos de las Comunidades Autónomas catalana y madrileña, que se disputaban el presunto privilegio de acoger tal macroinstalación, con "victoria" final para la propuesta madrileña. El citado promotor, por lo demás, y según la prensa comunicaba, no dudaba en reclamar, para adoptar la decisión que mejor le conviniere, incluso la inaplicación de determinada legislación general, o su modificación puntual adaptándola a la casuística concreta de 
su proyecto. Nos referimos a legislación reguladora de aspectos como la salud (prohibición del tabaco en espacios públicos cerrados), el juego (permisividad de acceso al juego a menores o ludópatas reconocidos), las condiciones urbanísticas y de edificación (para Cataluña, la regulación existente en relación con la proximidad del aeropuerto de Barcelona constituía una gran dificultad), las condiciones relativas a los derechos laborales, etc.

Duele tener que decirlo: resulta obscena, ya no desde el punto de vista político sino jurídico, la puja planteada entre ambas comunidades autónomas por lograr los "favores" de Mister Adelson. Y lo digo con esa rotundidad porque parece que no se recuerde el artículo 103 de la Constitución Española (CE): "La Administración pública sirve con objetividad los intereses generales... con sumisión plena a la ley y al Derecho.” ¿Podemos entender que esa sumisión se cohonesta con la vulneración o modificación ad personam de legislación como la citada? ¿Podemos aceptar que dicha conducta se rige por la objetividad cuando es fruto de los requerimientos concretos de un empresario determinado? Se ha argüido como justificación la existencia de un "interés general" digno de protección, cual sería, en términos generales, la inversión asociada al proyecto con sus consecuencias de generación de empleo. Parece que ello, por sí mismo, sea suficiente para demoler cualquier impedimento legal existente. Pero no debemos olvidar que el concepto "interés general" no puede ser un instrumento para la arbitrariedad, ni que uno de los valores superiores de nuestro ordenamiento jurídico es la igualdad (artículo 1 CE), una de cuyas vertientes, como se ha dicho, es la igualdad ante la ley. $Y$ recordemos nuevamente, aunque seamos reiterativos, que cuando el artículo 103 CE habla de la necesidad de que la Administración sirva los "intereses generales", se refiere a "con objetividad y sumisión plena al derecho".

Más sobre las previsiones de la Constitución: los extranjeros en España (como Mr. Adelson) gozarán de las libertades públicas que garantiza el Título I (sobre los derechos y deberes fundamentales) en los términos que establecen los tratados y la ley (artículo 13.1). A partir del principio de igualdad ante la ley (artículo 14), ¿cabe la modificación de una legislación general a instancias de un particular que actúa con ánimo de lucro, sea español o extranjero? Podríamos preguntarnos así, aunque sea de modo retórico: la grosera intervención en lo público de Mr. Adelson, en connivencia con los líderes políticos de las Comunidades Autónomas citadas, indicando qué legislación prefiere que se modifique, ¿no conculca la restricción que el artículo 13.2 aplica a los extranjeros en cuanto a participar directamente en los asuntos públicos que prevé el artículo 23?

Apartémonos, de todas formas, de estas reflexiones metajurídicas y analicemos el asunto desde la perspectiva local y legal. Una vez el Sr. Adelson ha decidido que sea Alcorcón el municipio "afortunado", podemos repetir aquí, mutatis mutandis, las consideraciones formuladas cuando hablábamos de los cementerios nucleares. En concreto: los efectos sobre el medio ambiente (pensemos en los recursos hídricos necesarios, la contaminación potencialmente generada...), el transporte, la movilidad (competencias locales, como se ha dicho), ¿se manifestarán únicamente en relación con Alcorcón, o trascenderán a otros municipios vecinos? Si las mareantes cifras de visitantes y empleados del complejo lúdico que se han facilitado se acercan a tan sólo su mitad, parece obvio que se generará un impacto trascendental en, al menos, las materias citadas y que repercutirá de manera inevitable fuera del término municipal de Alcorcón. No en vano las negociaciones han estado dirigidas por la Comunidad Autónoma madrileña, no por el Ayuntamiento de Alcorcón. Pero resulta que, por poner un ejemplo, hay un pueblo, Carranque, de la provincia de Toledo, que pertenece a otra Comunidad Autónoma, y se encuentra a menos de 30 kilómetros de Alcorcón. Quien dice ese pueblo, puede citar otros no muy alejados de Alcorcón. Pues bien, ¿notarán dichos pueblos el efecto de la instalación de Eurovegas? Si la respuesta es, aunque sea parcialmente, afirmativa, ¿no debería haberse oído a la Junta de Castilla-La Mancha, en este caso, en el proceso de toma de decisiones?

Por otra parte, se puede argumentar que la Comunidad de Madrid es competente, de acuerdo con el artículo 148.1, apartados 13) y 18) de la CE, en materia de fomento del desarrollo económico de su comunidad y de promoción y ordenación del turismo en su ámbito territorial, atendiendo a las finalidades que, según se ha explicado, persigue el proyecto en cuestión. El propio Estatuto de Autonomía de la Comunidad de Madrid (artículo 26) le atribuye competencias exclusivas en, entre otras materias, ordenación del territorio, fomento del desarrollo económico, promoción y ordenación del turismo, ocio, casinos, espectáculos públicos, ordenación y planificación de la actividad económica... Pero no es menos cierto que algunas de las características del proyecto Eurovegas ponen en cuestión la competencia exclusiva del Estado en otras materias, como por ejemplo las bases y coordinación general de la sanidad (si pensamos en la petición de exclusión de la legislación relativa a la prohibición del tabaco en los centros de trabajo), asunto relacionado con el derecho a la salud como parte integrante del derecho a la vida y a la integridad física (artículo $15 \mathrm{CE}$ ), cuya protección en régimen de igualdad se reserva al Estado de manera exclusiva en el artículo 149.1.1) CE. Recordemos también que el artículo 139.1 CE establece que todos los españoles tienen los mismos derechos y obligaciones en cualquier parte del territorio del Estado, por lo que cualquier disposición que vulnere en cualquier sentido esta norma será flagrantemente anticonstitucional (por ejemplo, un régimen de derechos laborales para los trabajadores de Eurovegas diferente al resto de españoles). En la misma 
línea argumentativa de preservación de la igualdad ante la ley (artículo $14 \mathrm{CE}$ ), habrá que permanecer atentos a cualquier regulación excepcional en materia de exenciones o bonificaciones tributarias, acceso de menores a los locales de juego, etcétera. Y no se arguya que tal precepto se circunscribe a los españoles, porque el artículo 13 dispone que los extranjeros gozarán en España de las libertades que garantiza el Título I (que contiene entre otros, como bien es sabido, el artículo 14) en los términos que establecen los tratados y la ley; al respecto, mis conocimientos jurídicos no llegan al extremo de hallar cualquier tratado o ley vigente que reconozca una posición de preeminencia a un extranjero sobre un español (en España) en cuanto a igualdad ante la ley...

Así pues, en este asunto entendemos que la aprobación de la instalación de Eurovegas correspondería a la Comunidad Autónoma de Madrid siempre que concurran, al menos, las siguientes circunstancias:

- Que su ámbito material de actuación no traspase los límites de la propia Comunidad en cuestiones como la movilidad, el medio ambiente, el transporte, la movilidad... Y todo ello habría de quedar plenamente acreditado en el expediente correspondiente, en función de los informes y memorias pertinentes.

- Que el régimen de funcionamiento del complejo no comporte la aplicación de exclusiones totales o parciales a leyes generales de ámbito superior que defienden intereses públicos con arreglo al principio de igualdad ante la ley.

- Que las decisiones que adopte en este asunto la Comunidad de Madrid no comporten en ningún caso un tratamiento discriminatorio (en materia tributaria, por ejemplo) con respecto a otros ciudadanos madrileños. Por decirlo con palabras muy claras: no es de recibo que una Administración pública, bajo el paraguas del concepto "interés público o general", legisle ad personam una normativa encaminada a favorecer a (y posiblemente inducida por) una empresa determinada.

\section{LOS GRANDES CENTROS DE DISTRIBUCIÓN COMERCIAL. EL EJEMPLO CATALÁN}

De la misma naturaleza podemos considerar otros debates, como el de las grandes implantaciones comerciales, dado que lo que se discutía en parte, según el enfoque que guía este trabajo, era si los Ayuntamientos podían per se autorizar determinados equipamientos comerciales, atendiendo a que su ámbito de atracción, y por tanto sus características (de movilidad, de transporte, de contaminación, etc.) tienen un potencial efecto supramunicipal. Tales efectos supramunicipales eran los que justificaban aparentemente las licencias de Administraciones superiores, en este caso las autonómicas. Un ejemplo paradigmático en esta cuestión lo constituye la normativa catalana que ha regulado esta materia, guiada siempre, con independencia del color político del Gobierno de turno, por una directriz tuitiva del pequeño comercio urbano, que se consideraba en situación de riesgo competitivo ante las grandes empresas de distribución comercial. Debe recordarse, aunque sea a efectos informativos, que las sucesivas consejerías o departamentos competentes en materia de comercio han sido regidas siempre por Convergencia y Unió o por Esquerra Republicana de Cataluña, partidos que se disputan tradicionalmente el voto del pequeño empresario catalán.

Así, las sucesivas legislaciones sectoriales habían mantenido unas cautelas importantes ante las potenciales nuevas implantaciones de grandes equipamientos comerciales, sometiéndolas a requisitos que la DSMI prohibió directamente: los relativos a una prueba económica mediante la cual se demuestre la existencia de una necesidad económica o de una demanda en el mercado, o que se evalúen los efectos económicos, posibles o reales, de la actividad... Tal era la línea argumental de las antecedentes normativas reguladoras catalanas, que pretendían con ello preservar y garantizar la existencia de un modelo comercial catalán propio fundamentado en un tejido comercial urbano constituido fundamentalmente por pymes (sin embargo, todo sea dicho, cualquier paseo por cualquier eje comercial urbano de cualquier ciudad mediana o grande nos muestra las mismas marcas y enseñas comerciales, las mismas franquicias, con lo que en realidad no hallamos vestigio de la singularidad del comercio local autóctono. Parece que, a ojos del legislador autonómico catalán, ello no incide en la preservación del modelo comercial propio). Para ello, dicha normativa impedía la apertura de determinadas tipologías comerciales, o dificultaba enormemente su implantación, mediante unas condiciones que sustraían a los municipios cualquier capacidad de decisión. Todo ello, como se ha dicho, basándose posiblemente en una interpretación cuando menos discutible del principio de subsidiariedad, según el cual la competencia ha de trasladarse a una Administración de mayor ámbito cuando las funciones correspondientes sobrepasan el nivel local. $Y$ decimos discutible por cuanto no se halla aquí en juego una controversia sobre las posibilidades de actuación de los Gobiernos locales, sino que estamos ante una decisión basada en un prejuicio (en el sentido etimológico de la palabra, juicio previo) de naturaleza política, y por tanto opinable: se consideraba que lo conveniente para Cataluña era un modelo comercial determinado, y como tal modelo no podía dejarse al albur de las decisiones municipales, se determinaba que correspondía al Gobierno autonómico tomar las decisiones pertinentes. Por ello, y a partir de la DSMI, se ha recurrido ahora a los criterios relativos directa o indirectamente al principio de subsidiariedad, como veremos en seguida. 
Todo ello se fundamentaba, a su vez, aunque sea sólo en parte, en los riesgos asociados a la carrera de intereses que hemos visto en los apartados anteriores (cementerios nucleares, Eurovegas) que se podía suscitar entre los diferentes Ayuntamientos, que esperarían como agua de mayo la instalación en sus términos municipales de grandes equipamientos comerciales que indudablemente habrían de atraer riqueza al municipio elegido. Al respecto, se argüía como ejemplo la remota implantación de cierto gran establecimiento en un pueblo muy pequeño al lado de Mataró, ciudad de más de 100.000 habitantes: ello comportaba previsiblemente, también, una competencia atroz que podría afectar no sólo al pequeño comercio urbano de esa localidad, sino también al de los municipios vecinos, que experimentarían una fuga de clientela hacia el nuevo gran equipamiento.

Como se ha dicho, la normativa catalana hubo de ser modificada a raíz de la aplicación de la DSMI, promulgándose para ello el decreto ley $1 / 2009$, de 22 de diciembre, de Ordenación de los equipamientos comerciales. Tal decreto ley mantiene, no obstante, la existencia de las Ilamadas licencias comerciales, cuyo otorgamiento se reserva el Gobierno autonómico a partir de unos criterios de valoración (artículo 15), que ya no contemplan expresamente el requisito prohibido de la prueba económica. Tales criterios, actualmente, se circunscriben a la adecuación del proyecto al planeamiento urbanístico vigente (¡no faltaría más!), a la movilidad generada (con especial atención a la incidencia en la red viaria y las infraestructuras públicas -sin que sepamos muy bien a qué se refiere esa incidencia en las infraestructuras-, y a la existencia o no de transporte público colectivo suficiente), a la incidencia ambiental y al impacto e integración paisajística. Se restringe así la libertad de establecimiento, puesto que tan sólo se permite la instalación de medianos y grandes establecimientos comerciales (aquellos que tienen una superficie de venta igual o superior a 800 metros cuadrados) en los municipios de más de 5.000 habitantes o que sean capital de comarca; y, concretamente, los grandes establecimientos comerciales territoriales (de superficie igual o superior a 2.500 metros cuadrados) sólo son admisibles en la "trama urbana consolidada" (TUC) de los municipios con población superior a 50.000 habitantes o que sean capital de comarca (artículo 9, puntos 3 y 4 ). Pero es que además la delimitación y aprobación de la TUC no corresponde a los Ayuntamientos, sino que es competencia de la Dirección General de Urbanismo de la Generalitat de Catalunya, a propuesta de cada Ayuntamiento. ${ }^{4}$ (Es preciso apuntar que las limitaciones que establecen los puntos 3 y 4 del artículo 9 están recurridas ante el Tribunal Constitucional, si bien su suspensión ha sido levantada, por lo que mientras no se dicte sentencia tienen vigencia).

Vemos pues, que con independencia de los criterios de valoración que hemos citado, el hecho es que los Ayuntamientos no disponen de la facultad legal de autorizar aquellos establecimientos que les pueden reportar más beneficio e incluso más ingresos fiscales. Y todo ello, según la norma reguladora, en aras de la preservación de la "cohesión social”, la cual se entiende como necesaria para la "sostenibilidad pretendida" (?), que "implica necesariamente la prosecución de equilibrios económicos en lugar del tradicional crecimiento lineal y acumulativo"; en aras también de la consecución del equilibrio territorial, de la potenciación de un modelo de ciudad compacta, de reducción de la movilidad para evitar desplazamientos innecesarios que congestionan las infraestructuras públicas e incrementan la contaminación atmosférica (¿por qué no se prohíben las "operaciones salida” típicas de determinadas fechas, por la misma razón?)... Éstos son algunos de los objetivos pretendidos con dicho decreto ley (artículo 4.2).

Pero estos objetivos, en cambio, no parecían verse afectados cuando se intentaba atraer a Eurovegas a Cataluña. Ni deberían de resultar afectados, imaginamos, tampoco si un municipio de una Comunidad Autónoma limítrofe que no disponga de una normativa de esta índole permitiera la instalación de un equipamiento comercial de 25.000 metros cuadrados a dos kilómetros de la frontera con Cataluña, por poner un ejemplo...

¿Qué podemos deducir, entonces, de la existencia de esta normativa? Pues que sencillamente consiste en una laminación de la autonomía local a partir de una interpretación sesgada del principio de subsidiariedad. Efectivamente, lo que han deseado y desean los sucesivos Gobiernos autónomos catalanes es reservarse las grandes decisiones en materia comercial, argumentando para ello la defensa de intereses generales de ámbito territorial superior al municipal. Y eso pese a que el propio Estatuto de Autonomía de Catalunya reconoce a los Gobiernos locales competencias propias en, entre otras materias, ordenación del territorio y urbanismo, la regulación del establecimiento de autorizaciones comerciales, la protección del medio ambiente... claro, todo ello "en los términos que determinen las leyes" (artículo 84 del Estatuto de Autonomía). Resulta curioso que el decreto ley 1/2009, además, prevé que las declaraciones responsables sobre establecimientos no sometidos al régimen de licencia comercial han de ser remitidas a la Dirección General de Comercio del Gobierno autónomo, de manera que únicamente se tramitan enteramente en el municipio las aperturas sujetas al régimen de comunicación (establecimientos con superficie de venta inferior a 800 metros cuadrados). ¿Cómo se compatibiliza ello con la competencia municipal relativa al establecimiento de autorizaciones comerciales que acabamos de ver en el artículo 84 del Estatuto? Podemos decir, en este caso, que ya no se trata de una competencia "en los términos que determinen las leyes",

4 Ver, en este sentido, F. LÓPEZ PÉREZ, El impacto de la Directiva de servicios sobre el urbanismo comercial, Atelier, Barcelona, 2009. 
sino que este decreto ley concreto sencillamente borra de un plumazo lo previsto en el Estatuto de Autonomía en esta materia, puesto que el Ayuntamiento ya no "autoriza" nada, sino que se limita su intervención a ser sujeto receptor de una "comunicación"... De esta manera, en realidad, nos hallamos ante el hecho de que un Decreto Ley vacía de contenido un Estatuto de Autonomía aprobado mediante Ley Orgánica, referéndum, etcétera.

\section{CONCLUSIONES: LA ATRIBUCIÓN Y EL REPARTO DE LAS COMPETENCIAS DESDE EL PUNTO DE VISTA JURÍDICO}

Como hemos comprobado con el análisis de los supuestos que hemos visto, la atribución o no de competencias a las entidades locales está dependiendo en muchas ocasiones de decisiones no fundamentadas estrictamente en consideraciones jurídicas, sino en criterios políticos.

Ello no es censurable per se: parece razonable que se implementen las políticas que desee adoptar un Gobierno democráticamente elegido, sea éste central, autonómico o local. Dicha implementación, no obstante, debe hacerse con rigor jurídico, atendiendo a las normas vigentes y modificándolas, si se considera preciso, con arreglo a los procedimientos legalmente establecidos. Pero no olvidemos que la CEAL forma parte de nuestro ordenamiento jurídico, con rango de Tratado y carácter de fuente primaria, y por tanto resulta inexcusable su aplicación en sus propios términos. Así, cuando su artículo 3 define la autonomía local como "el derecho y la capacidad efectiva de las Entidades locales de ordenar y gestionar una parte importante de los asuntos públicos, en el marco de la ley, bajo su propia responsabilidad y en beneficio de sus habitantes", debemos entender tal autonomía local a la luz de la cláusula de subsidiariedad contenida en el artículo 4.2 de la misma CEAL: "las Entidades locales tienen, dentro del ámbito de la Ley, libertad plena para ejercer su iniciativa en toda materia que no esté excluida de su competencia o atribuida a otra autoridad". Así lo recoge, por ejemplo, el F.J. quinto de la Sentencia del Tribunal Supremo de 21 de mayo de 1997. No obstante, la configuración material de esta autonomía pugna invariablemente, cuando los intereses en juego son de naturaleza supramunicipal, con las restricciones derivadas de las leyes autonómicas o estatales. Nótese, aunque sea un matiz todo lo leve que se quiera, que mientras el artículo 3 de la CEAL se refiere a la ley, en minúscula, como marco de la autonomía local, el artículo 4 nos habla del ámbito de la Ley, con mayúscula, referida pues a la ley en el sentido formal. El matiz puede tener trascendencia en cuanto que obligue a las autoridades de ámbito territorial superior al municipal a tramitar y aprobar una Ley (o un Decreto Ley, en su caso) para poder limitar la autonomía municipal en una materia de su competencia, y no un instrumento jurídico de carácter inferior (como por ejemplo, un Decreto que apruebe un plan sectorial).

Habrá que proceder, pues, en cada caso a analizar si realmente están en juego intereses supramunicipales que justifican la intervención normativa y/o de ejecución material de una Administración territorial superior a la local. Y este análisis no se debe efectuar, o considerar cumplidos sus objetivos, mediante una simple argumentación teórica de carácter más o menos retórico, que invoque sagrados principios pero sin concretar de qué manera se ven afectados. Es decir, se propone que cualquier instrumento normativo (con rango de Ley) en tal sentido vaya acompañado de unas memorias o informes que efectivamente justifiquen y demuestren la incidencia de la materia en el interés general de carácter territorialmente superior al municipio. No basta con argumentar que algunos o muchos clientes de un hipermercado serán de municipios distintos al de su implantación, sino que habrá que demostrar que ello genera unas consecuencias que requieren una regulación supramunicipal, y especificar tales consecuencias. Lo contrario podría llevar al absurdo de considerar la restricción de apertura de restaurantes de postín en ciudades como Madrid o Barcelona, por poner dos ejemplos, puesto que atraerían muchos clientes de otros municipios cercanos.

Están en juego demasiados intereses, no sólo económicos (que también): se trata de intereses de contenido jurídico, como la atribución y el reparto de competencias sectoriales entre Administraciones de diferente ámbito territorial y -en muchas ocasiones también- de diferente color político. Seamos todos, pues, rigurosos, y atendamos a la naturaleza de cada tema en cuestión para dilucidar hasta qué punto debe prevalecer la autonomía local como principio básico, o hasta qué punto se ha de atender a su modulación por el principio de subsidiariedad en aplicación del último inciso del artículo 4.3 de la CEAL: "La atribución de una competencia a otra autoridad (diferente de la local) debe tener en cuenta la amplitud o la naturaleza de la tarea o las necesidades de eficacia o economía". Este doble motivo, además, nos induce a una nueva reflexión.

En primer lugar, la sustracción de una competencia a las autoridades locales puede tener su origen en función de la amplitud o naturaleza de la tarea. Se trata pues de una causa material, relacionada con, o bien la incapacidad previsible del poder local para llevar a cabo la tarea en cuestión, o bien la especial naturaleza de dicha tarea. El primer caso parece relativamente fácil de argumentar, a partir de un informe técnico donde se ponga de manifiesto la insuficiencia de recursos específicos para acometer dicha tarea; el segundo, en cambio, se presta a más riesgo de discusión, al introducir un concepto jurídico indeterminado (la naturaleza) que indudablemente nos conducirá a 
un análisis ponderado de todo el asunto. Para ello podremos recurrir a la doctrina jurisprudencial, claro está, pero quizá sea tan operativo como ello la aplicación en la práctica de las Administraciones de los principios que rigen las relaciones entre ellas, contemplados en el artículo 3.2 de la LRJAP: el principio de cooperación y colaboración, en cuanto a sus relaciones, y los criterios de eficiencia y servicio a los ciudadanos en cuanto a su actuación. Es decir, en el momento de calificar la materia en cuestión para atribuir la competencia a una Administración en detrimento de otra, habrá que analizar de qué forma se garantiza mejor un servicio eficiente a los ciudadanos (recordemos que se entiende por eficiencia la consecución de los máximos objetivos con el menor número de recursos posible) y, a partir de tal análisis, impulsar si es preciso una decidida colaboración entre las Administraciones potencialmente concurrentes. Y, a su vez, para definir el "servicio" ofrecido o prestado a los ciudadanos deberemos poner atención en los servicios que se conceptúan como de carácter local en la LRBRL, para así comprobar en cada caso si se trata de servicios primariamente de competencia local.

La segunda causa de sustracción de competencia a las Administraciones locales se define en función de las necesidades de eficacia o economía. Llama la atención al respecto, en primer término, la disyuntiva o: parece que lo más lógico hubiera sido incorporar en su lugar una copulativa, una y. Y ello por cuanto, en resumen, coincidiría así de una manera bastante aproximada con el concepto "eficiencia". Efectivamente, una lectura e interpretación literal de este precepto podría conducir a unas consecuencias posiblemente indeseadas: conseguir muchos objetivos (eficacia) pero a un coste desmesurado (sin economía), o, al contrario, utilizar escasos recursos provocando alcanzar unos objetivos realmente parvos. No se conseguiría así, en ninguno de ambos supuestos, la prestación de un servicio eficiente a los ciudadanos. Por lo tanto, es opinión de quien suscribe que es conveniente atender a los principios de la LRJAP para interpretar correctamente esta disposición de la CEAL, y más aún teniendo en cuenta que la LRJAP es posterior en el tiempo a la CEAL, por lo que sus criterios han de iluminar la aplicación de cualquier norma con trascendencia en las relaciones entre Administraciones públicas.

Sin ir más lejos, y siguiendo a Beltrán Aguirre ${ }^{5}$, distingamos por ejemplo entre urbanismo (competencia local por naturaleza) y ordenación del territorio (competencia autonómica), todo ello a partir del análisis de la doctrina constitucional contenida en el Auto que comenta en su artículo, y que comporta un menoscabo material de las competencias municipales en relación con la ordenación del territorio, y restrinjamos la autonomía local cuando sea necesario mediante una Ley, no mediante un Plan sectorial aprobado por decreto. En relación a este análisis del autor citado, nótese que, como se ha dicho, el Estatuto de Autonomía de Cataluña atribuye a los Ayuntamientos competencias propias en ordenación del territorio. Ello no puede significar sino una interpretación divergente sobre en qué consiste la "ordenación del territorio": lo que para dicho autor (a partir de la opinión del Tribunal Constitucional) es de ámbito director o supralocal, para el legislador autonómico catalán no es más que una vertiente o cara del prisma del urbanismo local. Pongámonos de acuerdo, al menos, en los conceptos básicos.

O dicho de otro modo: plasmemos en la práctica cotidiana uno de los pilares que rigen las relaciones entre las Administraciones públicas, según el artículo 4 LRJAP: el principio de lealtad institucional. Este principio se manifiesta en una doble vertiente, positiva y negativa, o, si se prefiere "ad intra" o "ad extra". Así, en el ejercicio de las competencias propias, cada Administración ha de ponderar la totalidad de los intereses públicos implicados. Nótese que hablamos de intereses públicos, no privados, por lo que habrá que delimitarlos adecuadamente. También han de ayudar, en su propio ámbito, a las otras Administraciones para su ejercicio de competencias de manera eficaz. Por otro lado, deben respetar las competencias ajenas (no inmiscuirse, dicho de otro modo) y facilitar la información que otras Administraciones necesiten sobre la actividad desarrollada en el ejercicio de sus propias competencias.

Se trata, en fin, de ser realmente "leales", sin tergiversar ni forzar los argumentos de manera espuria con la finalidad de asegurarnos una competencia material determinada por razones de interés político o económico, aun a sabiendas de que lo estamos haciendo así (y no pretendo en absoluto incidir en el ámbito penal con el uso del término "a sabiendas").

Porque, entre los intereses generales que justifican la invocación de la cara negativa del principio de subsidiariedad, también está el respeto a la autonomía local en toda su extensión y naturaleza. Pero, sobre todo, porque hay un principio superior que continuamente está siendo sometido, en esta discusión sobre las competencias de las Administraciones territoriales, a unas pruebas de estrés posiblemente superiores, si se me permite la comparación, a las que padeció la banca, o incluso a las que la banca hace padecer a los ciudadanos con frecuencia: el principio de seguridad jurídica. Esperemos que este último principio supere estas pruebas de estrés con más éxito.

5 BELTRAN AGUIRRE, José Luis. "El menoscabo de la autonomía local con ocasión de la implantación de infraestructuras y dotaciones mediante instrumentos de ordenación del territorio: a propósito del ATC 251/2009, de 13 de octubre”. Revista Aranzadi Doctrinal n. ${ }^{\circ} 2 / 2010$ (Tribuna). Pamplona, 2010. 


\section{NOTA FINAL}

Con posterioridad al envío de este artículo, y mientras se procedía a evaluar su contenido antes de aprobar su publicación, han tenido lugar dos acontecimientos que vale la pena comentar brevemente.

En primer lugar, parece ser que finalmente el complejo Eurovegas no se instalará en España. Así que la carrera entre Comunidades Autónomas a que hacía referencia en el artículo se ha saldado con un fiasco, o, si se me admite la comparación, con la carrera propia de un canódromo, donde los galgos se desesperan y dejan sus energías por el camino en busca de una liebre inalcanzable. Claro que, por el camino, quizá también nos hemos (se han) dejado bastantes jirones de legitimidad en sus esfuerzos, a mi juicio.

En segundo lugar, la modificación de la Ley de Bases de Régimen Local operada por la Ley 27/2013, de 27 de diciembre, de racionalización y sostenibilidad de la Administración Local, desvirtúa de facto algunas de las referencias legales comentadas en el artículo (así, por ejemplo, las relativas a las competencias locales en materia de protección de los consumidores), pero aun así considero que las reflexiones plasmadas mantienen su virtualidad o vigencia. Sobre todo, puesto que intento analizar las relaciones entre los conceptos de autonomía local y subsidiariedad. Otra cosa, que quizá diera para muchos artículos sesudos, sería plantearnos dónde y cómo quedan tanto la autonomía local como el principio de subsidiariedad a partir de dicha Ley 27/2013, pero eso ya es harina de otro costal...

\section{BIBLIOGRAFÍA}

ARozAmENA SieRrA, Jerónimo (2002). "El Derecho Local en la Doctrina del Consejo de Estado”. Consejo de Estado, Imprenta Nacional del Boletín Oficial del Estado. Madrid, pp. 16-17. Revista Aranzadi Doctrinal n. ${ }^{\circ} 2 / 2010$ (Tribuna).

BeLTRÁN AGUIRRE, José Luis. (2010) “El menoscabo de la autonomía local con ocasión de la implantación de infraestructuras y dotaciones mediante instrumentos de ordenación del territorio: a propósito del ATC 251/2009, de 13 de octubre." Pamplona.

FERNÁNDEZ, Elvira y GIMÉNEZ, Eva. Els principis de subsidiarietat, proporcionalitat, descentralització i autonomia local i les seves conseqüències per a la regulació del règim local a Catalunya. Ponencia presentada en el Seminario sobre "Gobierno local y organización territorial: subsidiariedad y descentralización", organizado por el Consorcio Universidad Internacional Menéndez Pelayo de Barcelona, Centro Ernest Lluch. Barcelona, 8 y 9 de octubre de 2001.

LÓPEZ PÉREZ, F. (2009), El impacto de la Directiva de servicios sobre el urbanismo comercial. Barcelona. Atelier.

MIR I BAGó, Josep (2000), Manual de Govern Local. Barcelona: Federación de Municipios de Catalunya. 